\title{
Genotype by environment interaction and yield stability of hybrid maize varieties evaluated in three locations of mid altitudes of Rwanda
}

\author{
Rwasimitana F. ${ }^{\text {a*, Ukozehasi Ca }}$, Ngaboyisonga C. ${ }^{\text {, }}$ Eva J. ${ }^{\text {c }}$
}

a*University of Rwanda; College of Agriculture Animal sciences and Veterinary medicine(UR-CAVM)

${ }^{\mathrm{b}}$ Rwanda Agriculture and Animal Resources Development Board(RAB)

${ }^{c}$ Swedish University of agriculture(SLU)

\begin{abstract}
A multi-environment yield trial is important to understand the genotype by environment interaction and to select high performing and stable crop varieties. The aim of this study was to identify high yielding and stable hybrid maize varieties for mid altitudes of Rwanda, to compare the performance of new hybrid varieties with commercial checks, and to determine the extent of genotype by environment interaction. Maize is a staple crop used to fight hunger and malnutrition in developing countries. Different varieties have been released to increase yield including Open Pollinated Varieties (OPVs) and hybrids. Genotype by Environment interaction is an issue that all breeding program need to overcome. In the future, improved varieties will be needed in order to increase income for farmers and help in food security Field experiments were conducted to assess the performance and the stability of 27 maize varieties in the mid altitudes zone of Rwanda in the Cyabayaga, Rubona and Bugarama sites. The experimental design was alpha lattice $(0,1)$ with a Randomized Complete Block Design (RCBD). Data were collected for a number of characters i.e. silking, Antesis-Silking Interval (ASI), plant height, plant aspect, ear per plant, husk cover, ear aspect, ear rot and grain yield. Data were analyzed by GenS Stat statistical computer package, Discovery Edition. ANOVA and AMMI analysis were applied to assess the performance and the stability of varieties and the degree of genotype by environment interaction $(\mathrm{G} \times \mathrm{E})$. In addition, Principal Component Analysis (PCA) and cluster analysis were conducted to assess relationships between varieties. The results showed that RHM1706, RHMM1701, RHM1409, RHMM1707, WH509, RHMM1704, RHM407, WH101, RHMM1710, RHMM1708, PAN53 and RHM104 were stable across locations. Furthermore, the evaluated varieties were found to cluster into five groups. Varieties found to be most stable are recommended for further use.
\end{abstract}

Keywords: Open pollinated varieties, Genotype by Environments, Hybrid varieties, 


\section{Introduction}

Agriculture is a major pillar of the Rwandan economy. It provides direct employment to more than $70 \%$ of Rwandan people, many of whom are small-scale farmers living in rural areas and lacking adequate resources. The agricultural sector still contributes about $33 \%$ of the national Growth Domestic Product (NISR, 2016). However, a main challenge is the current productivity gap, with a difference in yield of $50 \%$ to $70 \%$ between farmers' fields and researchers' plots for staple crops such as maize (2.2 t/ha versus $7 \mathrm{t} /$ ha on average) and soybean $(0.8 \mathrm{t} / \mathrm{ha}$ versus $2.5 \mathrm{t} / \mathrm{ha}(\mathrm{FAO}, 2016)$. The low agricultural productivity in Rwanda is a result of several constraints. Rwandan agriculture is rain-fed, and hence more exposed to weather-related risks, especially to severe, frequent, and prolonged drought periods. Declining in soil fertility, mainly due to the lack of nutrient recovery causes important losses in agricultural yields. The land holding is extremely small ranging from 0.5 ha to 1.1 ha leading to the high percentage of small-scale subsistence farming. This affects the economy at both household and national levels farmers. The small land size per household is insufficient for supporting household food needs throughout the year and for providing incomegenerating activities to its members. This, in turn, leads to large imports of staple crops (World Bank and CIAT, 2015) The use of agricultural inputs is very low. The use of improved seed ranges from $1 \%$ to $25 \%$ while mean fertilizer application is about $21 \%$ depending on the crop. The formal

seed systems and value chains in Rwanda is still dominated by the public organizations for production, distribution and/or commercialization. The parallel informal seed systems supply $75 \%$ to $99 \%$ of the seed depending on the crop commodity. The seed supplied through informal system is of poor quality and come predominantly from farmer saved seed or is sourced from local markets (Promar, 2012).

Maize (Zea Mays) is a major cereal crop worldwide. It is used as food for human and feed for animals and constitutes raw materials for food and non-food industries (Khalil et al., 2011). It is a leading crop in Rwandan agriculture and it is used by many farmers for food and feed (Sallah et al., 2009). In 2007, the Government of Rwanda (GoR) initiated the Crop Intensification Program (CIP) with the aim of ensuring food security and improving livelihoods of small scale rural families. Within this program, maize was together with seven other crops, i.e. rice, wheat, cassava, potato, beans, soybean, cooking and dissert banana, chosen as the ones mainly contributing to food security (Minagri, 2010). Maize has an important role in the fight against hunger in developing countries. Rwanda contributes in this fight through a desire to increase the maize production from $125,000 \mathrm{MT}$ up to $650,000 \mathrm{MT}$. For success, the area of cultivation needs to be increased. Also, improved varieties will be needed to boost yield through increased resistance towards diseases, drought and lodging. The use of hybrids may be preferential because of its high yielding capacity compared to open pollinated varieties (Kutka, 2011). Genotype by environment is of great concern in order to maintain productivity of maize in different areas. The performance of varieties in terms of yield, disease resistance and drought tolerance need to be evaluated in different locations (Fatma, 2011). In the past years' maize was grown in high altitudes in Rwanda, but nowadays it is grown all around the country due to the development of new released varieties such as hybrids, open pollinated varieties and commercial (Ngaboyisonga et al., 2016). There is high demand of 
maize seed for the increase of production through the development and use of high yielding varieties. In Rwanda, the use of improved varieties will help in increasing yield. Major constraints are present that lead to a decrease in production of maize e.g.: drought, diseases and less availability of improved varieties in the whole country (Mulinga, 2014), new policies like the crop intensification program(CIP) will contribute to the release of new varieties and will also make these varieties available to the farmers (Ngaboyisonga et al., 2016) However, at present, some of the available released varieties are limited to cultivation within certain environments (Ngaboyisonga et al., 2014)

\section{Materials and Methods}

\subsection{Location of the study and Maize varieties used}

This study was conducted in three sites of the mid altitudes of Rwanda that comprised Bugarama, Rubona and Cyabayaga sites. Rubona is located at the altitude of 1,692 masl in the southern province. It has a bimodal rainfall with $1,170 \mathrm{~mm} /$ year of precipitation. Foliar disease is not severe and drought is occasionally occurring in this location. The Cyabayaga site is located at the altitude of 1,370 masl. It has a bimodal rainfall with $850 \mathrm{~mm} /$ year of precipitation. It is vulnerable of Turcicum Leaf Blight (TLB), Grey Spot (GLS) and there is frequent drought appearance compared to other site diseases. Bugarama is located at the altitude of 968 masl. It has a bimodal rainfall with $1,000 \mathrm{~mm} /$ year of precipitation. It is a hot spot of Maize streak virus (MSV) and Drought happens occasionally (Table 2.1), Twenty-seven maize varieties were used in the experimental trials. They comprised 13 new Rwanda Agriculture Board (RAB) hybrid varieties, six RAB pre-released hybrid varieties, six commercial hybrid varieties from regional seed companies were used as checks together with two OPVs from RAB. Among the six commercial checks, two were from Seed Co Ltd, two from Western Seed Company Ltd (WSC) and two from PANNAR Ltd. All RAB hybrid varieties were Three Way Cross Hybrid (TWCH) varieties (Table 2.2) 


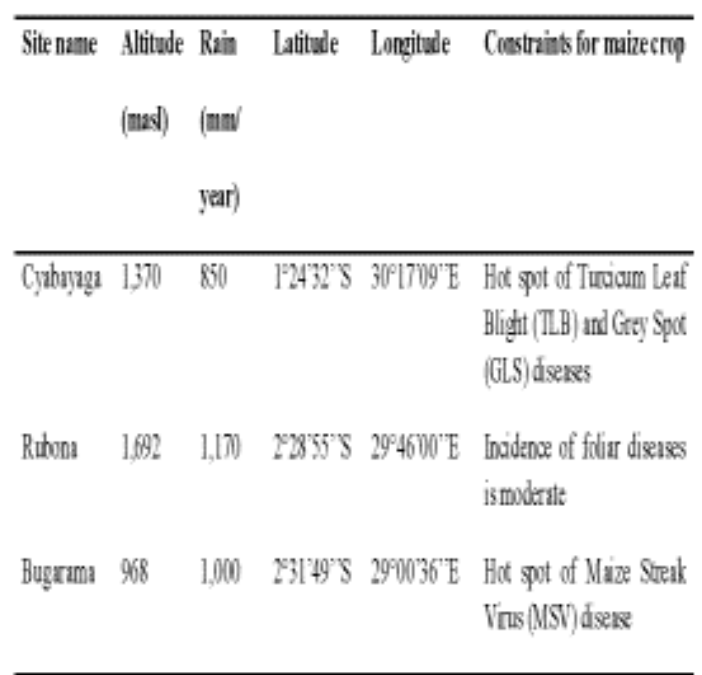

2.1 Location Characteristics of the study

\begin{tabular}{|c|c|c|c|c|c|}
\hline No & Names & Pedigrees & Type & Origin & Status \\
\hline 1 & RHMM1701 & CML202/CML203//CML445 & Hybrid & RAB & New \\
\hline 2 & RHMM1702 & CML 442 CML $539 \%$ CML 445 & Hybrid & RAB & New \\
\hline 3 & RHMM1703 & CML 442/RML 0008/CML445 & Hybrid & RAB & New \\
\hline 4 & RHMM1704 & CML 444/CML $489 /$ CML 445 & Hybrid & RAB & New \\
\hline 5 & RHMM1705 & RML $0002 / R M L 0003 / C M L .445$ & Hybrid & RAB & New \\
\hline 6 & RHMM1706 & RML0004/RML 0014/CML. 445 & Hybrid & RAB & New \\
\hline 9 & RHMM1707 & RML 0006/RML 0009/CML 445 & Hybrid & RAB & New \\
\hline 8 & RHMM1708 & RML 0010/RML0009/CML445 & Hybrid & RAB & New \\
\hline 9 & RHMM1709 & RML 0013/RML 0014/CML 445 & Hybrid & RAB & New \\
\hline 10 & RHMM1710 & RML 0014/RML 0010/CML445 & Hybrid & RAB & New \\
\hline 11 & RHMM1711 & RML 0018/RML 0009/CML 445 & Hybrid & RAB & New \\
\hline 12 & RHMM1712 & RML0018/RML 0013/CML.445 & Hybrid & RAB & New \\
\hline 13 & RHMM130 & RML0003/RML0010/CML.216 & Hybrid & RAB & New \\
\hline 14 & RHM104 & CML 442 CML 444 CML 445 & Hybrid & RAB & Pre-released \\
\hline 15 & RHM1402 & CML $442 / \mathrm{CML} 444$ CML 488 & Hybrid & RAB & Pre-released \\
\hline 16 & R.HM1407 & CML 539/CML $444 / C M L 445$ & Hybrid & RAB & Pre-released \\
\hline 17 & RHM1409 & CML 539/CML $444 / C M L 488$ & Hybrid & RAB & Preteleased \\
\hline 18 & RHMM113 & RML 0004 RML $0010 /$ CML. 488 & Hybrid & RAB & Pre-released \\
\hline 19 & RHT132 & CML203/CML204/CML216 & Hybrid & RAB & Prefeleased \\
\hline 20 & $\operatorname{sc} 529$ & $\operatorname{sc} 529$ & Hybrid & Seed $C_{0}$ & Commercial check \\
\hline 21 & wH509 & WH509 & Hybrid & wsc & Commercial theck \\
\hline 22 & wH101 & wH101 & Hybrid & wsc & Commercial theck \\
\hline 23 & PAN53 & PAN53 & Hybrid & PANNAR & Commercial theck \\
\hline 24 & PAN-4m-21 & PAN-4m-21 & Hybrid & PANNAR & Commercial theck \\
\hline 25 & $\mathrm{SC} 403$ & $\mathrm{SC}_{403}$ & Hybrid & Seed Co & Commercial check \\
\hline 26 & Kigega & 2M607 & OPV & RAB & OPV Check \\
\hline 27 & ISARM101 & Pop. NYA & OPV & RAB & OPV Check \\
\hline
\end{tabular}

Table 2. 2: 27 maize varieties used in the study

\subsection{Data Collection and Experimental design}

The experimental design for this study was an Alpha lattice $(4 \times 6)$ with four replications, but it was analyzed as a Randomized Complete Block Design with four replications. Every plot comprised of two rows of 5-m length, distances within the rows were $0.75 \mathrm{~m}$ and between hills was $0.25 \mathrm{~m}$. Two grains were planted per hill and after two weeks a thinning was done to one plant/hill. Fertilizers were applied both at planting with NPK and thereafter a top dressing with urea was applied. The experiment was dependent on rain as the main supplier of water. The first weeding was done after one week and was thereafter continued throughout the growing season when it was needed.

This study was targeting high yielding varieties and grain yield was the important trait to record. Yield was recorded in all plots by measuring the total number of ears harvested in a plot and obtaining the fresh weight in $\mathrm{kg}(\mathrm{FW})$ after that a sample of ears was taken in the middle of ten selected ears from each plot and this sample was used to check the grain moisture content (GM) in \% using a portable moisture-meter. Grain yield (GY) in $\mathrm{t} / \mathrm{ha}$ at $15 \%$ of grain moisture was calculated using the formula below, where $\mathrm{A}$ is the distance (in $\mathrm{m}$ ) between rows and $\mathrm{B}$ the 
distance (in $\mathrm{m}$ ) between hills at planting, $\mathrm{C}$ the length (in $\mathrm{m}$ ) of harvested rows, and $\mathrm{D}$ the number of rows harvested: $\mathrm{GY}=10 \times \frac{\mathrm{FW}}{\mathrm{A} \times(\mathrm{B}+\mathrm{C}) \times \mathrm{D}} \times \frac{100-\mathrm{GM}}{100-15} \times 0.8$.

Other agronomic parameters collected included silking (d), the Anthesis to Silking Interval (ASI) (d), plant height (m), plant and ear aspects (scale of 1 to 5). Silking was recorded as observed in days after planting, where the numbers of days were noted when up to a half of the plants in the plot showed silks. Thereafter ASI was calculated by the difference between silking and Antesis. Hence, the Antesis was also recorded as the number of days from planting to when $50 \%$ of the plants in the plot shed pollen. Ten plant randomly selected to calculate average of plant height in the plot from the plant base up to the point where the tassel started to branch. The plant aspect was recorded as the brown husk stage when plants were still green and ears fully attained development. For each plot, characteristics such as plant and ear height, uniformity of plants, diseases and insect's damages and lodging were noted. Thereafter, a scale of " 1 " to " 5 " where " $1=$ not a single damage, $2=$ =some damage, 3=initial damage, 4= damage, 5=severe damage was used. The ear aspect was taken after harvest, but before taking a sample for moisture determination, by spreading the pile of ears in front of the plot and considering characteristics such as disease and insect damage, ear size, grain filling, and uniformity of ears on a scale of " 1 " to " 5 " where " $1=$ not a single damage, $2=$ some show damage, 3 =initial damage, $4=$ damage, $5=$ severe damage.

Data were analyzed by GenS stat computer package and AMMI was used to analyze the G×E interaction for silking, plant height and grain yield. The means and IPCA 1 (Interaction Principal Component Axis) scores were used to form the AMMI 1 biplot. The AMMI analysis of variance was performed using statistical computer package GenS stat, Discovery, $4^{\text {th }}$ Edition using (Buysse et al., 2004) and Microsoft excel helped for biplot construction.

\section{Results}

\subsection{Combined performance across locations}

The silking varied from 65.7 days (RHMM1712) to 77.8 days (RHMM150) with an average of 70.5 days. Eleven varieties, RHMM1712, SC403, RHMM1708, RHMM1710, RHMM1709, RHMM1711, RHMM1703, RHMM113, RHMM1706, RHM1407 and RHMM1705, reached silking inferior to 69 days on average, fourteen varieties reached silking between 70 days and 75 days whereas only two varieties, RHT132 and RHM150, reached silking superior to 75 days. Moreover, all the varieties had ASI inferior to 2.5 days on average (Table 4.5).

The results indicated significant differences between varieties for plant height at $\mathrm{P}<0.001$. The plant height varied from $1.78 \mathrm{~m}$ (RHMM1709) to $2.60 \mathrm{~m}$ (WH509) with an average of $2.27 \mathrm{~m}$. The varieties RHMM170, RHMM1706, RHMM1707, RHMM1708, RHMM1710, RHMM1711, RHMM1712, RHMM150, RHM104, RHM1402, RHM1407, RHM1409, RHMM113, RHT132, SC529, WH101, ISARM101, PAN-4m-21, SC403, Kigega and PAN53 had plant heights between $2.0 \mathrm{~m}$ and $2.5 \mathrm{~m}$ respectively (Table 4.5 ). The analysis of variance showed that differences between varieties for plant aspect were significant at $\mathrm{P}=0.006$. The plant aspect varied from 2.5 (PAN53 
and RHMM1704) to 3.2 (RHMM1709 and Kigega) with an average of 2.86. The varieties RHMM1702, RHMM1705, RHMM1706, RHMM1707, RHMM1708, RHMM1710, RHMM1712, RHM104, RHM1402, RHM1407, RHM1409, RHT132, PAN-4m-21, WH509, WH101, SC529 had plant aspect between 2.5 and 3.0, while six varieties had plant aspect above 3.0 (Table 4.5). The results of analysis of variance indicated significant differences between varieties for ear per plant at $\mathrm{P}<0.001$. The EPP varied from 0.9 (RHMM1711) to 1.2 (RHMM1708) with an average of 1. A total of 17 varieties, RHMM1701, RHMM1702, RHMM1704, RHMM1705, RHMM1706, RHMM1709, RHMM1712, RHM1407, RHMM113, RHT132, SC529, PAN53, ISARM101, SC403, Kigega and PAN-4m-21 had an average of EPP equal to 1.0. Furthermore, 7 varieties, RHMM1703, RHMM1707, RHMM1710, RHMM150, RHM104, RHM1402, RHM1409 and WH101 had an average of EPP equal to 1.1 (Table 3.1).The analysis of variance showed that differences between varieties for ear aspect were significant at $\mathrm{P}<0.001$. The ear aspect varied from 2.4 (PAN53) to 3.4 (SC529) with an average of 3.0 Twelve varieties, RHMM1702, RHMM1704, RHMM1707, RHMM1708, RHMM1710, RHMM1712, RHM1407, RHM1409, WH509, WH101, PAN-4m-21 and ISARM101 had ear aspect between 2.5 and 3.0. The varieties RHMM1701, RHMM1703, RHMM1705, RHMM1706, RHMM1709, RHMM1711, RHMM150, RHM104, RHM1402, RHMM113, RHT132, SC529, Kigega and SC403 had ear aspect equal or superior to 3.0 (Table 3.1). The analysis of variance showed significant differences between varieties for ear rot $(\mathrm{P}<0.001$ ). Ear rot varied from 1.9 (RHMM150) to 3.2 (SC529 and Kigega) with an average of 2.5. Twelve varieties RHMM1701, RHMM1703, RHMM1708, RHMM1709, RHMM1710, RHM1407, RHT132, WH509, ISARM101, PAN53, PAN-4m-21 and WH101 had ear rot inferior to 2.5. The varieties, RHMM1702, RHMM1704, RHMM1706, RHMM1707, RHMM1711, RHMM1712, RHM104, RHM1402, RHM1409, RHMM113 and SC403 had ear rot equal or superior to 2.5 and inferior to 3.0. Furthermore, three varieties Kigega, SC529 and RHMM1705 had ear rot superior or equal to 3.0 (Table 3.1). The results of analysis of variance revealed significant differences between varieties for grain yield $(\mathrm{P}<0.001)$. Grain yields varied on average from $5.07 \mathrm{t} / \mathrm{ha}$ (Kigega) to $9.40 \mathrm{t} / \mathrm{ha}$ (RHM1402) with an average of $7.11 \mathrm{t} / \mathrm{ha}$. The varieties RHMM1702, RHMM1703, RHMM1705, RHMM1711, RHMM1712, RHMM150, RHM1402, RHMM113, RHT132, SC529, SC403 and PAN-4m-21 had grain yield inferior to 7.11 t/ha whereas the varieties RHMM1701, RHMM1704, RHMM1706. RHMM1707, RHMM1709, RHM1409 and WH509 had grain yields between 7.11 t/ha and 8.0 t/ha. Five varieties PAN53, RHMM1710, RHM1407, WH101 and RHMM1708 had grain yields superior or equal 8.0t/ha and inferior 9.0t/ha (Table 3.1) 
Table 3. 1: General performance across locations

\begin{tabular}{|c|c|c|c|c|c|c|c|c|c|c|}
\hline No & Names & SIL & ASI & HT & PA & EPP & $\mathrm{HC}$ & $\mathbf{E A}$ & ER & GYD \\
\hline 1 & RHMM1701 & 74.8 & 1.1 & 2.14 & 3.0 & 1.0 & 3.3 & 3.0 & 2.2 & 7.27 \\
\hline 2 & RHMM1702 & 71.3 & 1.9 & 2.23 & 2.8 & 1.0 & 3.1 & 2.8 & 2.6 & 6.90 \\
\hline 3 & RHMM1703 & 68.6 & 2.3 & 2.34 & 3.0 & 1.1 & 3.0 & 3.0 & 2.1 & 6.63 \\
\hline 4 & RHMM1704 & 70.8 & 1.1 & 2.27 & 2.5 & 1.0 & 2.8 & 2.8 & 2.5 & 7.76 \\
\hline 5 & RHMM1705 & 68.9 & 2.0 & 2.18 & 2.7 & 1.0 & 3.0 & 3.1 & 3.0 & 6.19 \\
\hline 6 & RHMM1706 & 68.8 & 0.4 & 2.22 & 2.9 & 1.0 & 3.2 & 3.1 & 2.6 & 7.35 \\
\hline 7 & RHMM1707 & 69.6 & 1.8 & 2.30 & 2.8 & 1.1 & 3.1 & 2.9 & 2.5 & 7.79 \\
\hline 8 & RHMM1708 & 68.3 & 1.5 & 2.30 & 2.6 & 1.2 & 3.0 & 2.9 & 2.3 & 8.81 \\
\hline 9 & RHMM1709 & 68.5 & 1.3 & 1.98 & 3.2 & 1.0 & 3.3 & 3.1 & 2.4 & 7.10 \\
\hline 10 & RHMM1710 & 68.3 & 0.5 & 2.19 & 2.6 & 1.1 & 3.0 & 2.7 & 2.2 & 8.56 \\
\hline 11 & RHMM1711 & 68.5 & 1.9 & 2.30 & 3.1 & 0.9 & 3.2 & 3.3 & 2.6 & 5.33 \\
\hline 12 & RHMM1712 & 65.7 & 0.8 & 2.15 & 2.9 & 1.0 & 3.2 & 2.9 & 2.5 & 6.02 \\
\hline 13 & RHMM150 & 77.8 & 1.4 & 2.27 & 3.1 & 1.1 & 3.2 & 3.0 & 1.9 & 5.66 \\
\hline 14 & RHM104 & 70.0 & 0.9 & 2.31 & 2.8 & 1.1 & 2.8 & 3.0 & 2.5 & 9.40 \\
\hline 15 & RHM1402 & 71.0 & 1.2 & 2.29 & 2.8 & 1.1 & 2.8 & 3.1 & 2.8 & 6.98 \\
\hline 16 & RHM1407 & 68.8 & 0.9 & 2.22 & 2.8 & 1.0 & 3.0 & 2.8 & 2.3 & 8.08 \\
\hline 17 & RHM1409 & 70.0 & 0.6 & 2.26 & 2.7 & 1.1 & 2.9 & 2.9 & 2.7 & 7.73 \\
\hline 18 & RHMM113 & 68.6 & 2.1 & 2.21 & 3.1 & 1.0 & 3.1 & 3.3 & 2.5 & 6.31 \\
\hline 19 & RHT132 & 76.3 & 2.3 & 2.31 & 2.9 & 1.0 & 3.1 & 3.1 & 2.3 & 6.78 \\
\hline 20 & SC529 & 73.5 & 2.1 & 2.33 & 2.9 & 1.0 & 3.2 & 3.4 & 3.2 & 5.26 \\
\hline 21 & WH509 & 73.9 & 1.6 & 2.60 & 2.7 & 1.1 & 2.9 & 2.7 & 2.0 & 7.97 \\
\hline 22 & WH101 & 70.1 & 1.3 & 2.28 & 2.9 & 1.1 & 3.0 & 2.6 & 2.3 & 8.16 \\
\hline 23 & PAN53 & 73.8 & 1.8 & 2.39 & 2.5 & 1.0 & 3.0 & 2.4 & 2.2 & 8.99 \\
\hline 24 & PAN-4m-21 & 72.3 & 2.1 & 2.30 & 2.9 & 1.0 & 2.9 & 2.8 & 2.3 & 6.86 \\
\hline 25 & SC403 & 66.6 & 2.1 & 2.29 & 3.0 & 1.0 & 3.0 & 3.1 & 2.7 & 6.29 \\
\hline 26 & Kigega & 69.3 & 2.3 & 2.30 & 3.2 & 1.0 & 2.9 & 3.3 & 3.2 & 5.07 \\
\hline 27 & ISARM101 & 69.5 & 1.8 & 2.39 & 2.8 & 1.0 & 3.1 & 2.8 & 2.3 & 6.79 \\
\hline \multicolumn{2}{|c|}{ Mean } & 70.5 & 1.5 & 2.27 & 2.86 & 1.0 & 3.0 & 3.0 & 2.5 & 7.11 \\
\hline \multicolumn{2}{|c|}{ C.V. (\%) } & 3.5 & 95.1 & 8.3 & 17.3 & 12.2 & 14.5 & 15.3 & 30.3 & 18.7 \\
\hline \multicolumn{2}{|l|}{$\mathrm{F}$} & 16.16 & 1.94 & 3.83 & 1.91 & 2.06 & 1.14 & 3.03 & 2.24 & 9.07 \\
\hline \multicolumn{2}{|l|}{$P$} & $<0.001$ & 0.006 & $<0.001$ & 0.006 & $<0.001$ & 0.297 & $<0.001$ & $<0.001$ & $<0.001$ \\
\hline
\end{tabular}

SIL: Silking (d)

ASI: Anthesis-Silking Inerval (d)

HT; Plant height (m)

PA: Plant Aspect (1-5)

EPP: Ears per plant (Number)

HC: Husk Cover (1-5)

EA: Ear Aspect (1-5) ER: Ear Rot (1-5) GY: Grain yield (t/ha@ 15\% $\mathrm{H}_{2} \mathrm{O}$ ) 


\subsection{Analysis of genotype by environment interaction using AMMI model}

The AMMI analysis of variance for silking (Table 4.5) of the 27 varieties (19 new varieties under evaluation) across three locations indicated that the variation due to varieties and locations were highly significant $(\mathrm{p}<0.001)$. The varieties effects show only $1.7 \%$ of the treatment Sums Squares (SS), environments $79.3 \%$ while interaction effects were not significant and explained only $2.9 \%$ of the treatment SS. It further reveal that the first IPCAs (Interaction Principal Component Axis) was highly significant $(\mathrm{P}<0.05)$ and explained $80.41 \%$ of the interaction effects (Table 4.5$)$.

The AMMI analysis of variance for plant height (Table 3) of the 27 varieties (19 new varieties under evaluation) across three sites showed that the variation due to environments and G X E were highly significant $(\mathrm{p}<0.001)$. The varieties effects were not significant, locations effects indicated 95\% of the treatment Sums Squares (SS), while interaction of site and varieties effects explained $3.6 \%$ of the treatment SS. It further showed that the first IPCAs (Interaction Principal Component Axis) were highly significant $(\mathrm{P}<0.001)$ and explained $28.3 \%$ of the interaction effects (Table 4.5$)$. The AMMI analysis of variance for grain yield (Table 3 ) of the 27 varieties (19 new varieties under evaluation) across three sites showed that the variation due to varieties, environments and $\mathrm{G} \mathrm{X} \mathrm{E}$ were highly significant $(\mathrm{p}<0.001)$.

The varieties effects indicated that $23.1 \%$ of the treatment Sums Squares (SS), environments $59.1 \%$ while interaction effects explained only $17.7 \%$ of the treatment SS. It further showed that the first IPCAs (Interaction Principal Component Axis) were highly significant $(\mathrm{P}<0.001)$ and explained $61.67 \%$ of the interaction effect. (Table 4.5).

Table 3. 2: AMMI analysis of variance for silking, plant height and grain across locations

\begin{tabular}{lllllllllll}
\hline $\begin{array}{l}\text { Sources } \\
\text { variation }\end{array}$ & of & DF & \multicolumn{2}{l}{ Silking } & \multicolumn{4}{c}{ Plant height } & \multicolumn{3}{c}{ Grain yield } \\
\cline { 3 - 12 } & & SS & MS & F & SS & MS & F & SS & MS & F \\
\hline Total & 323 & 16,439 & 50.9 & - & 245.1 & 0.76 & - & $2,239.2$ & 6.9 & - \\
Treatments & 80 & 14,875 & 185.9 & $29.73^{* * *}$ & 220.1 & 2.75 & $30.31^{* * * *}$ & $1,799.1$ & 22.5 & $12.74^{* * * *}$ \\
Varieties & 26 & 2,627 & 101.1 & $16.16^{* * *}$ & 2.9 & 0.11 & $1.23^{\text {NS }}$ & 416.1 & 16.0 & $9.07^{* * * *}$ \\
Sites & 2 & 11,808 & $5,904.2$ & $529.47^{* * *}$ & 209.1 & 104.53 & $250.26^{* * *}$ & $1,064.4$ & 532.2 & $176.24^{* * *}$ \\
Sites/Replications & 9 & 100 & 11.2 & $1.78^{\mathrm{NS}}$ & 3.8 & 0.42 & $4.60^{* * *}$ & 27.2 & 3.0 & $1.71^{\mathrm{NS}}$ \\
Sites $\times$ Varieties & 52 & 439 & 8.5 & $1.35^{\mathrm{NS}}$ & 8.1 & 0.16 & $1.72^{* *}$ & 318.6 & 6.1 & $3.4^{7 * * *}$ \\
IPCA & 27 & 353 & 13.1 & $2.09^{* *}$ & 2.3 & 0.086 & $2.41^{* * *}$ & 196.5 & 7.3 & $4.12^{* * * *}$ \\
Residuals & 25 & 87 & 3.5 & $0.56^{\text {NS }}$ & 1.0 & 0.04 & $1.12^{\text {NS }}$ & 122.1 & 4.9 & $2.77^{* * *}$ \\
Error & 234 & 1463 & 6.3 & - & 8.3 & 0.04 & - & 412.9 & 1.8 & - \\
\hline
\end{tabular}




\subsection{Biplot of silking obtained by plotting the means}

The AMMI 1 biplot (Figure 4.2) showed that the varieties: RHM1704, RHMM1701, RHT132, WH509, RHMM1702, PAN53, PAN-4m-21, RHMM1710, SC529 and RHMM150 had average silking means superior to overall means (70.5days). The variety RHM1M150 was the highest silking means $>77$ days) and was close to IPCA1 axis (IPCA score <0.4). The varieties RHMM1407and RHMM1709 had very large IPCA1 scores (IPCA1 scores between +1.2 and 1.5 The varieties RHMM1402, RHMM1702, PAN53, PAN-4m-21and RHMM150 were placed at Rubona whereas the cluster made by varieties: RHM1704, RHMM1701, RHT132, RHMM1704, and SC529 groped together with Cyabayaga site.



Figure 3: 3: Biplot of silking obtained by plotting the means (d) against IPCA1 (d0.5) for 27 maize varieties 


\subsection{Regression of altitude (masl) onto silking (d)}

The regression of altitude onto silking showed that the regression coefficient was positive indicating that silking increased significantly with increasing altitude. The coefficient of determination was 0.62 indicating that the regression captured $62 \%$ of the variation. Furthermore, the correlation coefficient between altitude and silking was 0.79 implying that while the altitude was increasing it increased tremendously the silking (Figure 4.3.)

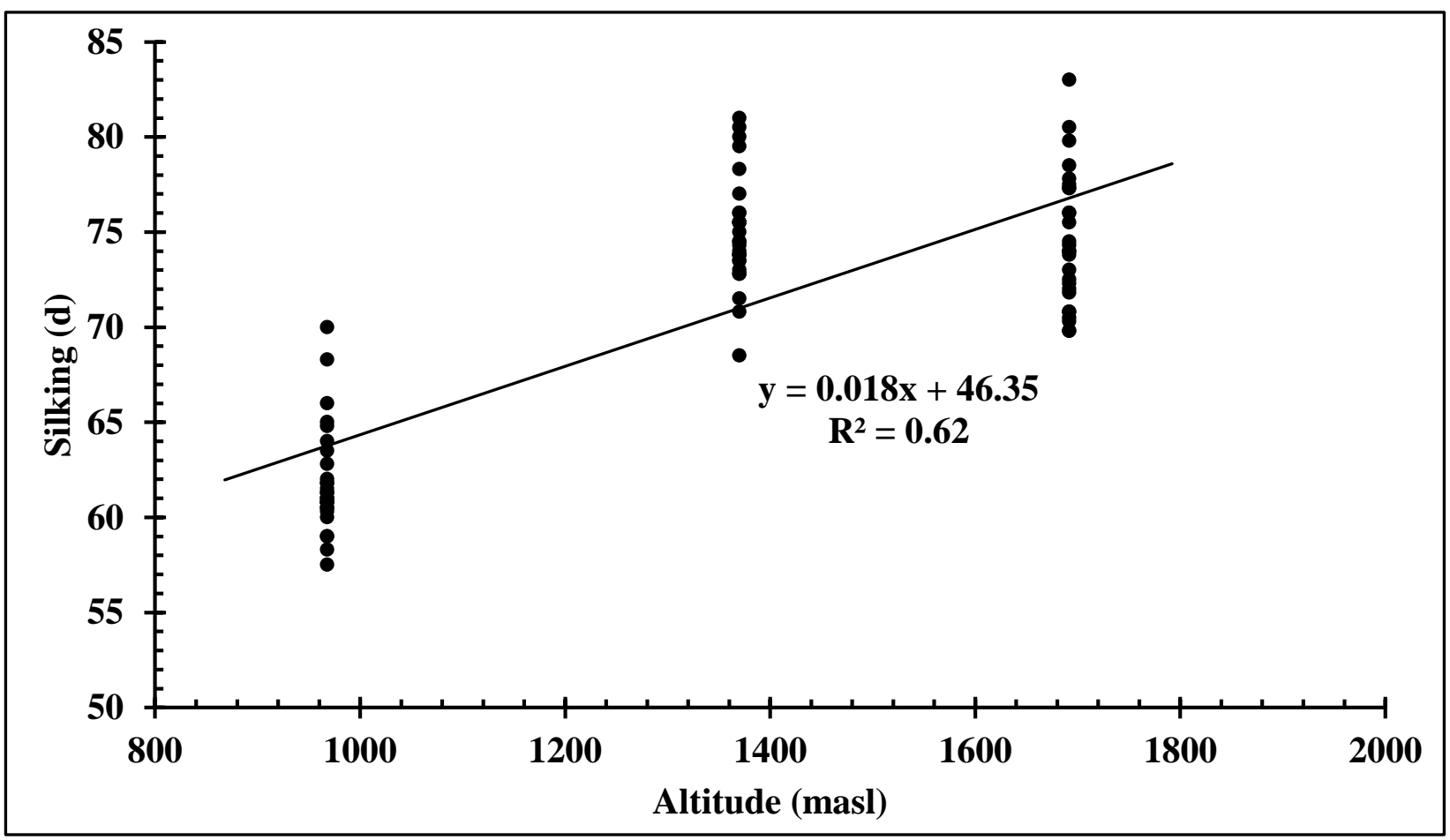

Figure3.4: Regression of altitude (masl) onto silking $(d)$

\subsection{Biplot of plant height and grain yield obtained by plotting the means ( $\mathrm{m})$}

The AMMI 1 biplot (Figure 3.5) showed that the varieties Kigega, RHM1704, RHMM1707, RHT132, WH509, RHMM1703, PAN53, PAN-4m-21, RHMM1710, SC529, ISARM101, RHM104, RHM1409 and RHMM17110 had average plant height means superior to overall means $(2.3 \mathrm{~m})$. The variety WH509 was the highest in plant height means $(2.7 \mathrm{~m})$ and was close to IPCA 1 axis (IPCA score $<0.1$ ). The varieties Kigega and RHMM1709 had very large IPCA 1 scores (IPCA 1 scores between +0.4 and -0.4 The varieties RHMM1402, Kigega, RHMM1708, RHMM150, SC529, RHM1704, RHMM1707, RHMM1708, PAN-4m-21 and WH509 were placed at Bugarama whereas the cluster made by varieties RHMM1711, RHT132, ISARM101, PAN53 RHM1409, and RHM104 groped together with Cyabayaga site 
The AMMI 1 biplot (Figure 3.6) clearly showed that the varieties RHM1706, RHMM1701, RHM1409, RHMM1707, WH509, RHMM1704, RHM407, WH101, RHMM1710, RHMM1708, PAN53 and RHM104 had average grain yield means superior to the overall means ( $7.11 \mathrm{t} / \mathrm{ha})$. The variety RHM104 showed the highest yield (mean $>9 \mathrm{t} / \mathrm{ha}$ ) and was close to IPCA 1 axis (IPCA score <0.6). The cluster made by the varieties RHM1706, RHMM1701, RHM1409, RHMM1707, WH509, RHM407, WH101, Kigega, RHMM1705, RHMM1703, ISARM101, PAN-4m-21, RHMM113, RHM1402, RHMM1702 and RHMM1708 had IPCA 1 scores between -0.5 and +0.5. In this cluster, varieties RHMM113, RHMM1702, RHM1402, RHM1409 and WH101 were very close each other with IPCA scores between -0.3 and 0 . The variety SC529 had very large IPCA 1 scores (IPCA 1 scores approximately to +1.2). The varieties RHM1706, RHMM1701 and RHM1409 were placed at Rubona whereby the cluster made by varieties WH509, RHMM1704, RHM407, WH101, RHMM1710, RHMM1708, PAN53 and RHM104 grouped together with Bugarama site.

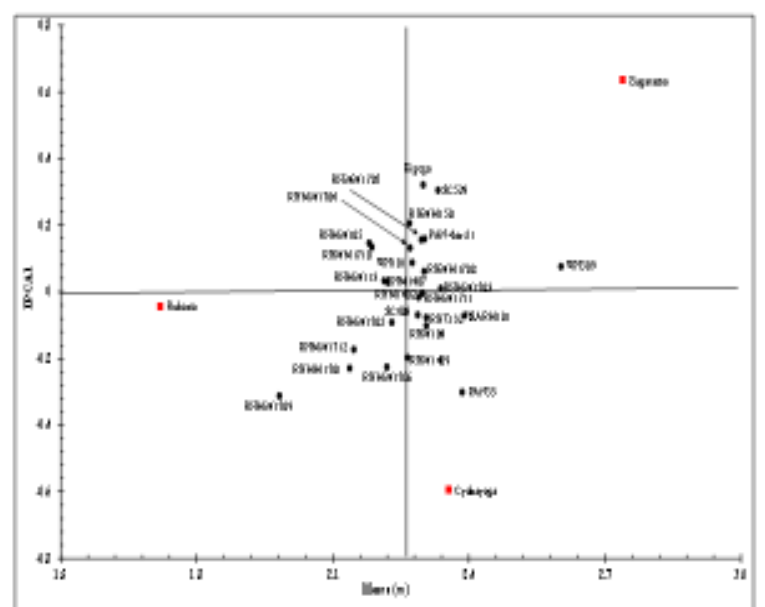

Figure 3: 5: Biplot of plant height obtained by plotting the means (m) against IPCAl (m0.5) for 27 matze varteties across locations

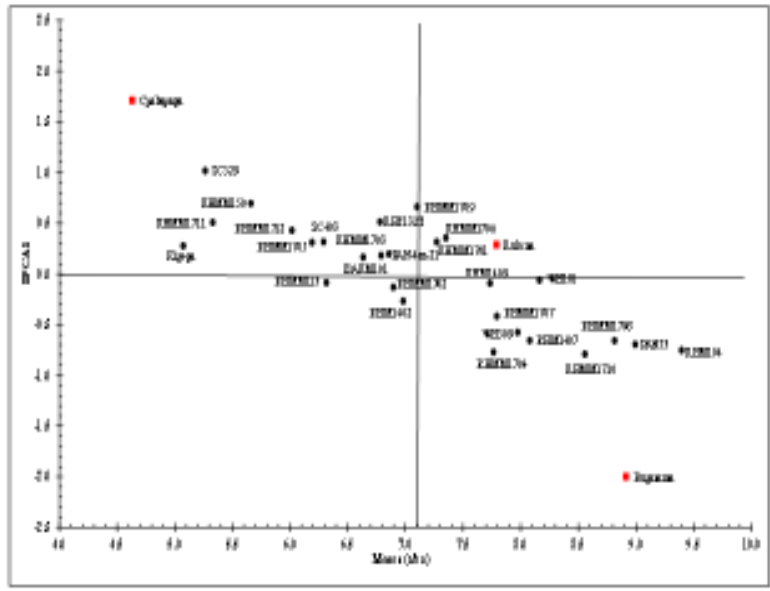

Figure 3:6: Biplot of grain yteld obtained by plotting the means (t/ha) against IPCAl [(t/ha)0.5] for 27 maize varieties 


\subsection{Principal Component Analysis (PCA) and cluster analysis}

The PCA biplot indicated that the PCA1 explained $24.8 \%$ of the variation and the PCA2 $19.6 \%$. PCA1 and PCA 2 together captured $44.4 \%$ of the variation. Furthermore, it showed that that many varieties were scattered whereas few of them formed distinct clusters such the cluster formed by RHM104, RHMM1704, RHM1407, RHMM1708 and RHM1710, the cluster formed by RHMM150 and RHT132, and the cluster formed by RHM1409, WH101, ISARM101, RHM1402, RHMM1703 and RHMM1702. None of these clusters comprised commercial checks except the last cluster which contained the check WH101 (Figure 4.6.).



Figure 3: 7: PCA biplot involving 27 maize varieties and 15 agronomic traits

\subsection{Cluster analysis showing the similarities of 27 maize varieties using 15 agronomic traits}

The cluster analysis showed that the pre-released hybrid RHM113 was similar to SC403 at 98\%, the commercial checks PAN-4m-21 and WH101 similar to the hybrid RHMM1703 at 93\%, the check SC403 similar to RHMM1711 at 93\%, the check SC529 similar to RHMM1702, RHM1705 and RHM1711 at 90\% and the checks PAN53, WH509 were similar to RHM1708, RHM1707, 
RHM1407, RHM1710, RHM104 and RHM1704 at 86\%. Furthermore, it revealed that the prereleased variety RHM1407 was similar to RHM1710 at 96\%, RHM104 similar to RHM1704 at 95\%, both RHM1407 and RHM104 similar to RHMM1710 and RHMM1704 at 93\%. Besides, they are similar RHM1707, RHM1708 at 90\% (Figure 4.7).

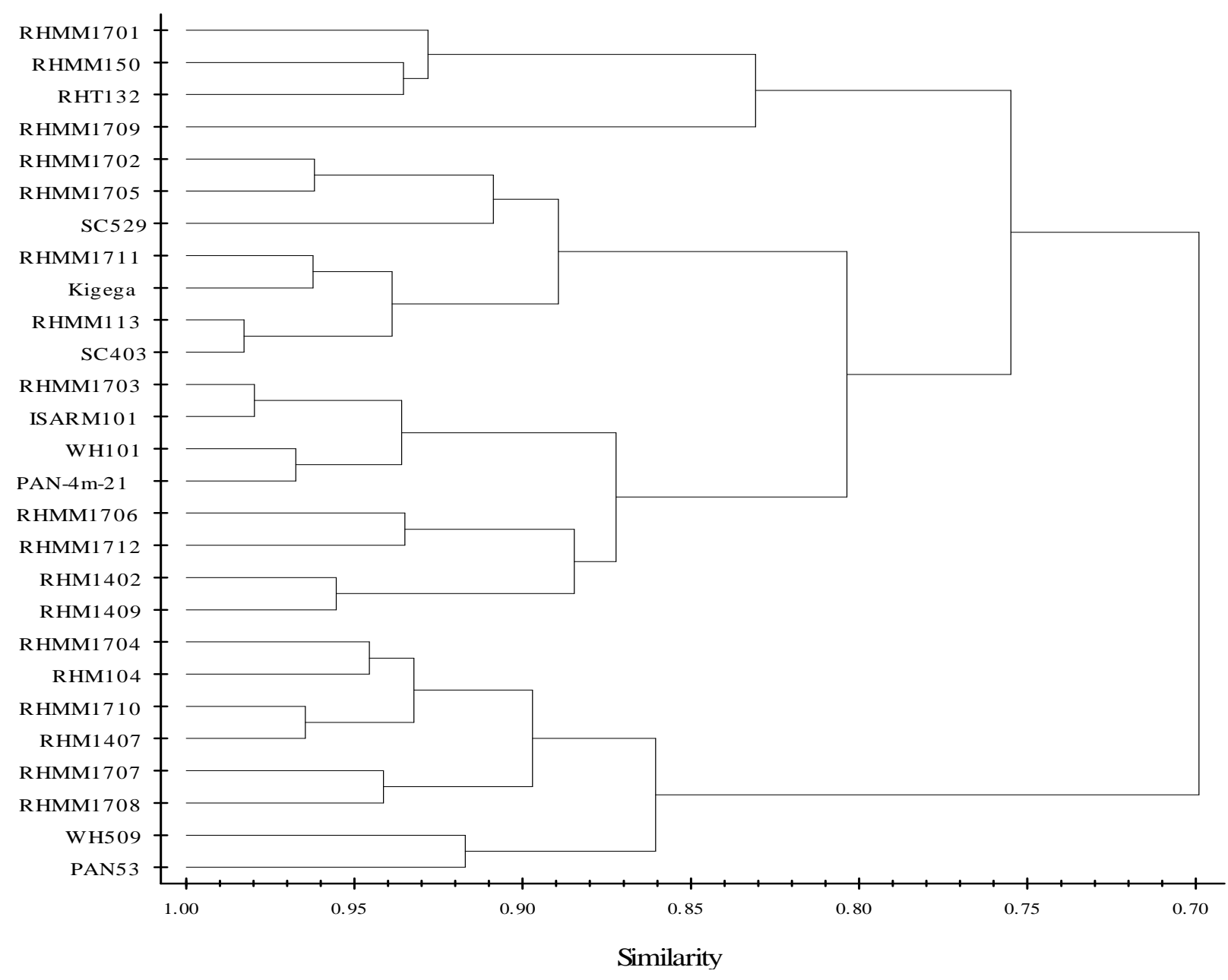

Figure4: 1: Dendogram showing the similarities of 27 maize varieties using 15 agronomic traits

\section{Discussion}

The combined ANOVA for all three sites and showed a significant difference for silking $(\mathrm{P}<0.001)$ among the evaluated varieties. The varieties were found affected by the environment, and especially in Cyabayaga site it was shown a delay was observed in silk emergence due to stressful conditions such as occurrence of drought. Also significant differences $(\mathrm{P}=0.006)$ was found for ASI, and it is known that a high ASI for more than three days' results in plants suffering of 
pollination problem thereby affecting yield. This study also showed a low yield in the maize grown in Cyabayaga which is a similar result was found by Beyene et al. (2012).

Plant height was also found significant different $(\mathrm{P}<0.001)$ among the cultivars over the three cultivation sites. Generally, maize grown in Bugarama resulted in the highest plant height as compared to other sites. It is a general perception that when plant perform better in vegetative stage i.e. grow more and higher, this will also lead to good performance in the reproductive stage, resulting in higher yield. Furthermore, the plant aspect differed significantly $(\mathrm{P}=0.006)$ among the varieties over the three locations, and a good plant aspect is also known to be correlated with high yield (Yan and Tinker, 2006).

The ear aspect was significantly $(\mathrm{P}<0.001)$ different among varieties over the three locations. This character is a good indicator of the quality of the cultivation for farmers, as a high value on the ear aspect normally result in high yield and this character is normally easily understood by the farmer., The ear rot was significantly $(\mathrm{P}<0.001)$ different among the varieties over the three locations. The ear rot is known to affect grain yield by decreasing the grain output of the plant. Furthermore, the grain yield differed significantly $(\mathrm{P}<0.001)$ among varieties over the three locations. A superior yield is always a major target goal within all breeding programs, and high yielding varieties are always selected and recommended to farmers. In cases when yield is not consistent across sites this is a problematic situation for the breeder and indicates that the varieties are not stable over locations. Here the yield of the investigated varieties was generally higher in the Bugarama site compared to the Rubona and Cyabayaga sites, respectively. The ANOVA also showed significant differences for ASI $(\mathrm{P}=0.011)$, plant height $(\mathrm{P}=0.002)$, ears per plant $(\mathrm{P}<0.001)$, ear rot which could explain the differences in yield, similarly as has also been the case in previous investigations (Dehghani et al., 2006; Adu et al, 2013).

In the AMMI analysis, the treatment variation was categorized into three types of variations (variation due to varieties main effects, variation due to sites main effects and variation due to combined varieties $\mathrm{x}$ sites effects). These three types of variations imply different suggestions: the varieties variation refer to general adaptations, sites effects variation is related to narrow adaptations while varieties variations combined together with varieties $\mathrm{x}$ sites represent large environments (Gauch, 2006).

The AMMI analysis for silking, plant height and grain yield of the 27 varieties across three sites reveal that the variation due to varieties effects accounted less than of the sites and interaction effects. The variation due to sites was higher than varieties together with interaction; which suggests that narrow adaptation was more important than broad adaptation. This means that varieties showed a ability to adapt to specific environments, which is in agreement with previous studies conducted on different crops including maize indicated that environmental variation contributed more than varieties and interaction effects (Ngaboyisonga et al., 2016), (Mukherjee et al., 2013; Beyene et al., 2012).

The AMMI 1 biplot for yield showed an ideal interpretation as varieties not far from the abscissa being responsible for the main effects, but the pattern along the ordinate indicate changes in interaction effects. Varieties with a high mean superior to generalized mean and an IPCA 1 score 
close to zero (near the abscissa) shows the variety being stable across environments (Yan et al., 2007). In this study, the varieties RHM1706, RHMM1701, RHM1409, RHMM1707, WH509, RHMM1704, RHM407, WH101, RHMM1710, RHMM1708, PAN53 and RHM104 showed average grain yield means superior to overall means and a IPCA 1 close to the axis, therefore being considered stable across environment, following interpretations from previous studies (Gauch, 2006; Yan et al., 2007). The varieties PAN53 and RHM104 have also been found stable over environments in previous studies (Ngaboyisonga et al., 2016). PCA is known as a method helping breeders to understand the pattern of a range of traits in a group of varieties identifying those with most suitable traits combination (Ali et al,.2014). In this study, the varieties were grouped in five clusters, and only one commercial variety in these, implying a relationship among the newly released varieties. This study was conducted in three sites for one season due to the limited time of a MSc education. During the season of evaluation, the Cyabayaga site was vulnerable to prolonged droughts that lead to low performance in that site.

\section{Conclusion}

This study was intended to identify hybrid high yield and stable hybrid maize varieties for mid altitudes of Rwanda. Therefore, trials were carried out in three different locations namely Cyabayaga, Rubona and Bugarama and a total of 27 varieties were used. Performance of new hybrid varieties was checked towards commercial check varieties to certify the identification of high yielding and stable varieties adapted to the mid altitude of Rwanda. Furthermore, the extent of genotype by environment interaction was evaluated in the study. The Results indicated that environments were diverse and a broad adaptation of the maize varieties was more important than a narrow adaptation. The varieties RHM1706, RHMM1701, RHM1409, RHMM1707, WH509, RHMM1704, RHM407, WH101, RHMM1710, RHMM1708, PAN53 and RHM104 were found stable across locations and therefore they could be used in mid altitude to increase maize production. This study also suggested the present commercial checks, PAN53 and WH509, to be replaced by RHM1708, RHM1707, RHM1407, RHM1710, RHM104 and RHM1704. The locations used in this study were found not enough to represent all zones of the mid altitude area of Rwanda, so more trials are needed to be conducted to understand a full picture. The results also showed that not all varieties are stable in mid altitudes of Rwanda and these varieties should therefore not be recommended to be used in the mid altitude. Furthermore, genotype by environment interaction was found influencing the performance of the varieties. Bugarama was the best site to grow maize and the varieties performed better at this site as compared to the two other sites used, were Rubona was found the second best site and Cyabayaga was the last in performance. 


\section{REFERENCES}

Adu, G.D., R. Akromah, M.S. Abdulai, K. Obeng-Antwi, A.W. Kena, K.M.L. Tengan m and H. Alidu. (2013). Assessment of Genotype by Environment interactions and Grain yield Performance of Extra-Early Maize (Zea Mays L.) Hybrids. Journal of Biology, Agriculture and Healthcare , Vol.3, No.12,pp 7-15.

Ali Kahraman, Mustafa Onder and Ercan Ceyhan. (2014). Cluster Analysis in Common Bean Genotypes (Phaseolus vulgaris L.). Turkish journal of Agricultural and natural science , 1:10301035.

Beyene, Y., Mugo, S. Mutinda, C., Tefera, T., Karaya, H., Ajanga, S., Shuma, J., Tenda, R, and Kanga,.(2011). Genotype by environment interaction and yield stability of stem borer resistant maize hybrid in Kenya. .African journal of biotechnology vol 10, 10: 4752-4758.

Beyene, Y., Mugo, S., Tefera, T., Gethi, J., Gakunga, J., Ajanga, S., Karaya, H, Musila, R.,Muasya. W., Tende, R. and Njoka, S. . (2012). Yield stability of stem borer resistantmaize hybrids evaluated in regional trials in East Africa. African Journal of Biotechnology, Vol. 6(2), pp. 77-83.

Buysse W, Stern R, Coe R. (2004). GenStat discovery edition for everyday use. Nairob: ICRAF.

Dehghani, H, Ebadi, A. and Yousefi, A..(2006). Biplot analysis of genotype by environment interaction for barley yield in Iran. Agronomy journal , 98:388-393.

Fatma, E. I(2011). Evaluation by envirnoment interactions in maize hybrids using GGE byplots analysis. crop breeding and aplied biotechnology , 11:1-9.

Gauch, H. (2006). Statistical analysis of yield trials by AMMI and GGE. crop sciences , 42:619633.

Khalil, A.I, Ur- Rahman, H., Ur-Rehman, N., Arif, M, Khalil, I. H, Iqbal, M., Hidayatullah, A.K., Sajjad, M. and Ishaq, M. (2011). Evaluation of maize hybrids for grain yield stability in NorthWest of Pakistan. Sarhad Journal of Agriculture, Vol.27, No.2.

Kutka, F. (2011). Open-Pollinated vs. Hybrid Maize Cultivars. Sustainability. 3: , 1531-1554.

Minagri. (2010). Evaluation report on crop intensification program. Kigali: International Center for Soil Fertility and Agricultural.

Mukherjee A.K Mohapatra N.K., B. L. (2013). Additive main effects and multiplicative interaction (AMMI) analysis of GxE interactions in rice-blast pathosystem to identify stable resistant genotypes. Africa Journal of Agriculture Res, Vol :8, pp 5492-5507.

Mulinga, N. N. (2014). Performance of hybrid maize introductions in the mid- altitudes zone of Rwanda. Scholarly agriculture journal of sciences Vol.4(11), November , 553-557.

Correspondent Person: rwasimitanafabrice@gmail.com

ORCID ID: https://orcid.org/0000-0003-3064-2365

Pre Print Version 
Ngabitsinze, J. C. (2014). Analysis of Economic Efficiency of Maize Production in Huye District in Rwanda. International Journal of Agriculture Innovations and Research , 2319-1473.

Ngaboyisonga, Nyombayire A, Gafishi M.K, Nizeyimana F, Uwera A, Ndayishimiye T, Karemera F. X, Mutanyagwa P, Gumisiriza G. and Gahakwa. (2016). Adaptability and genotype by envirnoment Interaction of maize commercial hybrid Varieties from East African seed companies in Rwanda Envirnoments. Global Journal of Agricultural Research Vol 4,No 2 , 32-40.

Ngaboyisonga. C, F. Nizeyimana, A. Nyombayire, M.K. Gafishi,. (2014). Identification of Elite, High Yielding and Stable Maize Cultivars for Rwandan Mid-altitude Environments. Springer International Publishing Switzerland, 165-178.

NISR, N. i. (2016). Statistical yearbook. KIgali-Rwanda: SYB(2016).

Sallah, P.Y.K., Mukakalisa S., Nyombayire A. and Mutanyagwa P. (2009). Response of two maize varieties to density and nitrogen fertilizer in the highland zone of Rwanda. Journal of applied biosciences 20 , 1194-1202.

Tyagi, S. D and Khan, M. H. . ( 2009). Genotypeby environment interaction and stability analysis for yield and its components in soybean (Glycine max L. Department of plant breeding and genetics K.P. , kmudasirhafiz@yahoo.com.

USDA, U. S. (2018). World Agricultural Supply and Demand Estimates. Washington DC: USDA Foreign Agricultural Service Office of Global Analysis IPA division.

Yan, W. and Tinker, N. A. . (2006). Biplot analysis of multi-environment trial data: Principles and application. Canadian Journal of Plant Science , . 86: 623-645. 